\title{
Aspectos socioeconômicos e ambientais do reuso de águas residuárias em uma comunidade rural localizada no município de Apodi-RN
}

\section{Aspects socioeconomic and environmental of the reuse of wastewater in a rural community in the municipality of Apodi-RN}

\author{
Maria Alcilene Morais ${ }^{1}$, Gleydson de Freitas Silva ${ }^{2}$, Francisco Aires Sizenando Filho ${ }^{3}$, Anderson Alves Santos, \\ Luara Lourenço Ismael Is $^{5}$
}

\begin{abstract}
Resumo: A utilização da água residuária na produção agrícola é uma alternativa sustentável do ponto de vista ambiental e, sobretudo econômica para a realidade da região Semiárida do Brasil. Este trabalho teve por objetivo caracterizar o perfil socioeconômico analisando o nível de satisfação de uma comunidade rural em relação ao reuso e seus benefícios sociais e ambientais. A pesquisa foi realizada no Projeto de Assentamento Milagre, localizado no município de Apodi no Estado do Rio Grande do Norte. A metodologia de análise foi por meio de aplicação de questionários com as famílias que correspondem um total de 26 casas. O período de aplicação dos questionários se deu no mês de junho de 2013. Constatou-se quanto aos aspectos socioeconômicos que as crianças de 0-3 anos de idade não dispõem de nenhum acompanhamento escolar. O estado civil dos chefes da família correspondia a $12 \%$ casados, $10 \%$ assumem uma união consensual e $1 \%$ dos assentados são viúvos. A maioria das famílias entrevistadas residem no próprio assentamento e 95\% dos moradores trabalham na própria agricultura. Em relação à percepção dos moradores quanto ao reuso de água, foi possível observar que dentre os entrevistados a maioria responderam que com a ausência de esgoto a céu aberto ocorreu uma redução da proliferação de insetos e vetores, resultando em uma visão mais agradável da comunidade.
\end{abstract}

Palavras-chaves: Efluente doméstico, sustentabilidade, qualidade de vida.

Abstract: The use of wastewater in agriculture is a sustainable alternative from an environmental point of view and especially economic for the reality of the semi-arid region of Brazil. This study aimed to characterize the socioeconomic profile and analyze the level of satisfaction of a rural community in relation to reuse and its social and environmental benefits. The survey was conducted in the settlement Miracle Project, located in the municipality of Apodi / RN. The analysis methodology was through questionnaires with families matching a total of 26 homes. The questionnaires application period took place in June 2013. It was found as the socioeconomic aspects that children 0-3 years old lacked any school support. The marital status of head of household accounted for $12 \%$ married, $10 \%$ are of consensual union and $1 \%$ of the settlers are widowers. Most families interviewed live on the settlements and $95 \%$ of residents work in agriculture itself. Regarding the perception of residents regarding water reuse was observed that among the respondents most responded that with the absence of open sewage there was a reduction of proliferation of insects and vectors, resulting in a more pleasant view of community.

Key words: Domestic effluent, sustainability, quality of life.

\footnotetext{
*autor para correspondência

Recebido para publicação em 17/06/2016; aprovado em 15/09/2016

${ }^{1}$ Mestra em Manejo do Solo e da Água, Universidade Federal Rural do Semiárido - UFERSA, Mossoró-RN; (84) 99631-0615, alcilenemorais@ ymail.com.

${ }^{2}$ Mestre em Manejo do Solo e da Água, Universidade Federal Rural do Semiárido - UFERSA, freitas.gleydson@hotmail.com

${ }^{3}$ Doutor em Fitotecnia , Universidade Federal do Ceará - UFC, eng.aires @ hotmail.com

${ }^{4}$ Metranda em Engenharia Civil e Ambiental, Universidade Federal da Paraíba - UFPB, luara_ismael@ hotmail.com

${ }^{5}$ Doutor em Engenharia Florestal, Universidade Federal de Lavras -UFLA, alvesanto@ hotmail.com
} 


\section{INTRODUÇÃO}

O reuso de efluentes quando feito de forma planejada representa em uma maneira de aumentar os benefícios sociais, econômicos e ambientais, na zona rural. Os autores Hurlimann, (2008); Dolnicar e Schäfer (2009), afirmam que, a percepção social sobre o reuso de água está relacionada a diversos componentes e pode ter um caráter positivo ou negativo sobre esta prática. Dessa forma, segundo os autores, entre os pontos mais relevantes destacam-se: o risco à saúde pública; os impactos positivos ou negativos ao meio ambiente; os custos e benefícios econômicos, sejam estes positivos ou negativos; confiança nas autoridades sanitárias e fatores culturais ou emocionais.

$\mathrm{O}$ reuso de água pode trazer benefícios econômicos, sociais e ambientais para as comunidades rurais, sendo uma alternativa sustentável para aumento da oferta de água, contribuindo também com uma gestão mais racional da demanda.

Para Hespanhol (2008), a percepção dessas comunidades a respeito do reuso está relacionada ao grau de informação que tenham acesso e a confiança nos interlocutores. A aceitação ou interesse da comunidade em relação à implantação do reuso de efluentes domésticos surge a partir da percepção social e do grau de risco a saúde que irá favorecer ou impedir essa prática ou a instalação de uma Estação de Tratamento de Efluentes (ETE), dentro da comunidade.

De acordo com Savi et al. (2008), estudos epidemiológicos comprovam que a água contaminada é responsável por diarreias, transmissão de febre tifoide, cólera, dengue, leptospirose, leishmaniose e propagação de outras doenças parasitárias, que representam as principais causas de morte de lactentes nos países em desenvolvimento.

Segundo pesquisas do Instituto Brasileiro de Geografia e Estatística - IBGE (2011) sobre os municípios, observa-se que a presença de esgoto a céu aberto prejudica comunidades em 1.031 municípios brasileiros correspondendo a $41 \%$ destes. No Nordeste, o Estado com mais municípios com pelo menos um impacto foi o estado de Pernambuco, apresentando $82 \%$ de esgoto a céu aberto (IBGE, 2011).

As crianças e os agricultores se encontram nas comunidades rurais são os mais propícios ao contado constante com o solo e a água, além disso, muitas vezes não possuem a consciência de fatores prejudiciais à saúde. O controle sanitário das águas reaproveitadas para irrigação é de grande importância para as condições de vida e qualidade ambiental, em destaque para os recursos naturais (solo e água), utilizados na produção agrícola que devem apresentar níveis satisfatórios de sustentabilidade, para posteriormente serem utilizados nas culturas.

Os dados da Pesquisa Nacional de Amostras por Domicílios (PNAD) evidenciam que $22 \%$ da população rural reside em domicílios que ainda não possui nenhum tipo de sistema de coleta de esgoto, e 54,3 \% recorrem a soluções não adequadas para tratamento dos esgotos domésticos, como por exemplo: fossas rudimentares, valas e despejo dos efluentes diretamente nos rios, lagos e mares, representando uma ameaça à saúde da população, principalmente das crianças as quais estão mais sujeitas ás doenças de veiculação hídrica (BRASIL, 2009).
As técnicas de tratamento adotadas para água de reuso em seus diversos fins, estão inseridas no conceito de sustentabilidade dos recursos ambientais. O desafio é gerar um efluente com condições menos impactantes no meio ambiente e sem riscos à saúde humana, isto é, gerar os seguintes benefícios ambientais e à saúde pública: não lançamento de esgotos em corpos de água superficiais; preservação dos recursos hídricos subterrâneos; conservação do solo, através da acumulação de "humus"; maior resistência do solo à erosão; aumento da produção de alimentos; saúde, qualidade de vida adequada ao desenvolvimento das populações.

A forma como o indivíduo ou a comunidade visualiza a prática do reuso, está intrinsecamente ligada não somente à compreensão do ambiente em que vive, mas também a como percebe o risco. (SCHAER-BARBOSA, 2014).

A percepção de risco, principalmente em face de novas tecnologias é sempre polêmica, devido ao temor do desconhecido e da sensação de perda de controle associada (SANTOS; FADUL, 2008).

Diante do exposto, objetivou-se caracterizar o perfil socioeconômico dos moradores do assentamento rural Milagre, localizada no município de Apodi no Estado do Rio Grande do Norte, analisando o nível de satisfação da comunidade em relação ao reuso de água e os benefícios sociais e ambientais, após a instalação da ETE na comunidade.

\section{MATERIAL E MÉTODOS}

O trabalho foi conduzido na unidade experimental de reuso de água de uma área comunitária de uso agrícola, pertencente ao Projeto de Assentamento Milagre, localizada no município de Apodi-RN, situado a $100 \mathrm{~km}$ de Mossoró$\mathrm{RN}$, sob as coordenadas geográficas $5^{\circ} 35^{\prime} 22^{\prime \prime}$ de latitude sul e 3754'09' de longitude oeste.

De acordo com a classificação de Köppen, o clima predominante na região é do tipo BSw'h', caracterizado por ser muito quente, seco e salubre, tendo predominância do clima semiárido, inserido no bioma caatinga. A temperatura máxima é de $37^{\circ} \mathrm{C}$ e mínima de $21^{\circ} \mathrm{C}$, com períodos chuvosos variando de janeiro a julho e seco de julho a dezembro. Os meses em que ocorrem as maiores precipitações são março a abril. Com média anual oscilando em torno de 600 e 700 mm. Já a insolação média da região, é de aproximadamente 3041 horas ano, com evaporação média de $2190 \mathrm{~mm}$ ano.

Investigou-se o reuso de águas residuárias e a percepção dos moradores rurais sobre os aspectos socioeconômicos e ambientais. $\mathrm{O}$ assentamento é formado por 30 famílias, cada uma destas inseridas em uma área média dividida em lotes de aproximadamente 19,6 ha e, ainda 50,7 ha de área coletiva (LIRA, 2010).

Todas as casas dos assentados dispõem de rede coletora e interceptora de esgoto, além de uma estação para tratamento preliminar e primário do esgoto doméstico bruto. Dessa forma, foi aplicado um questionário com as famílias do assentamento em 26 unidades habitacionais, durante o mês de junho de 2013.

O questionário foi aplicado com um membro de cada família, tendo como propósito obter informações acerca do perfil dos moradores da comunidade e do nível de aceitação 
destes sobre os benefícios socioambientais do reuso do efluente tratado.

O solo da área classifica-se como argiloso vermelho amarelo. Este solo apresenta relativa susceptibilidade aos processos erosivos em virtude da descontinuidade textural e estrutural ao longo do perfil (EMBRAPA, 2009).

\section{RESULTADOS E DISCUSSÃO}

\section{Perfil dos moradores da Comunidade Milagre}

Conforme pode ser observado na Figura 1, verifica-se que $77 \%$ das casas existentes no assentamento foram entrevistadas na pesquisa, e $23 \%$ se encontravam fechadas por motivo desconhecido, dessa forma, obteve-se uma representação para entrevista.

Figura 1. Percentual do número de casas visitadas no Assentamento Milagre, localizada no município de Apodi, Rio Grande do Norte

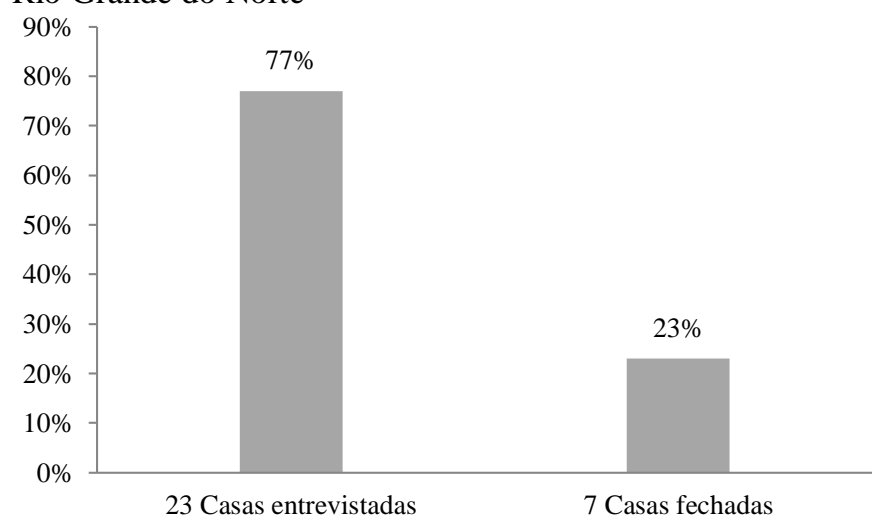

Fonte: Autores (2016)

Das residências analisadas, 09 destas são compostas de 01 a 03 membros na família, totalizando de 39\%, 08 casas possuem de 04 a 06 pessoas, totalizando 35\%, 05 casas possuem de 07 a 09 membros na família, totalizando $22 \%$ dos entrevistados e apenas 01 casa possui 11 membros como observa-se na Figura 2.

Figura 2. Percentual de membros de cada família analisada no Assentamento Milagre, localizada no município de Apodi, Rio Grande do Norte

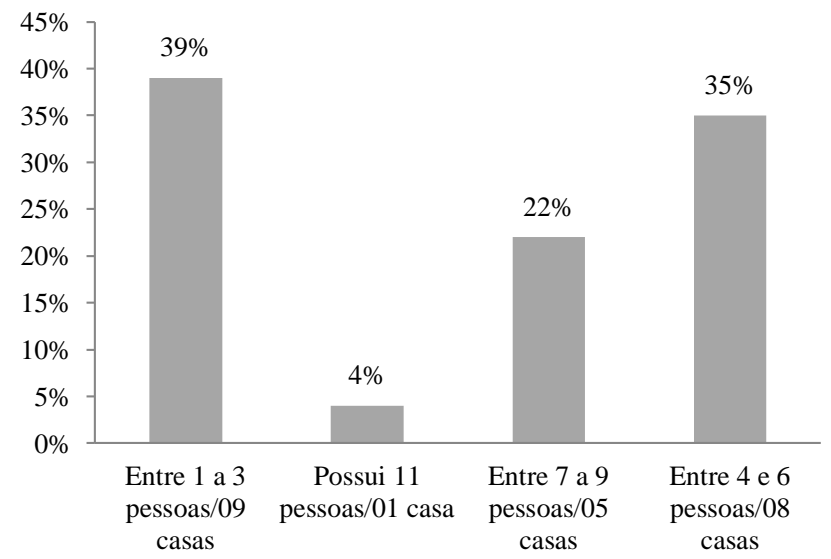

Fonte: Autores (2016)
A comunidade é formada por uma média de 89 membros. Em relação ao gênero $43 \%$ dos moradores são do sexo masculino e $33 \%$ do sexo feminino. A faixa etária de adolescentes entre 15 a 17 anos corresponde a $9 \%$ e a as crianças entre 0 a 14 anos se concentra em 15\% dos entrevistados, com ambos os sexos (Figura 3).

Figura 3. Porcentagem por sexo de adultos e por idade de crianças e adolescentes no Assentamento Milagre, localizada no município de Apodi, Rio Grande do Norte

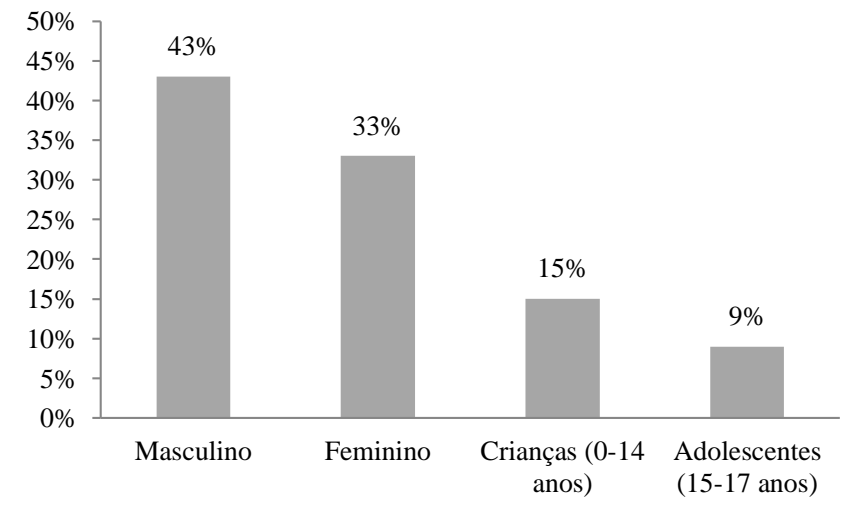

Fonte: Autores (2016)

No que se refere a naturalidade dos residentes do assentamento Milagre é possivel constatar que a maioria totalizando $93 \%$ dos moradores são naturais do município de Apodi-RN, uma vez que o centro urbano da cidade dispõe de hospital, com maternidade e posto de saúde. E os outros 7\%, são naturais de cidades circunvizinhas ou de localidades fora do estado do Rio Grande do Norte-RN, assim como mostrado na Figura 4.

Figura 4. Porcentagem por número do local de nascimento dos moradores no Assentamento Milagre, localizada no município de Apodi, Rio Grande do Norte

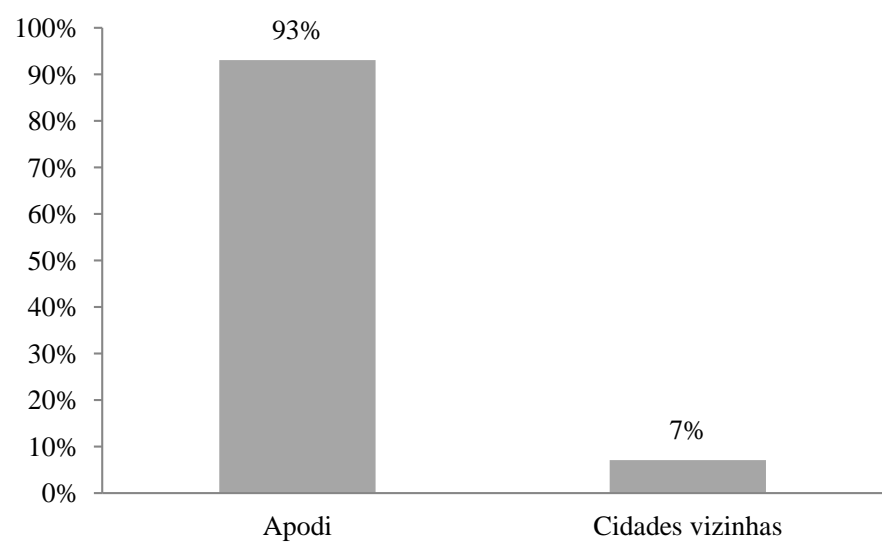

Fonte: Autores (2016)

Sobre o estado civil dos chefes das famílias, $89 \%$ destes são casados, $10 \%$ assumem uma união consensual e $1 \%$ dos assentados são viúvos, conforme observa-se na Figura 5. 
Figura 5: Porcentagem de moradores por Estado Civil dos responsáveis da Família no Assentamento Milagre, localizada no município de Apodi, Rio Grande do Norte

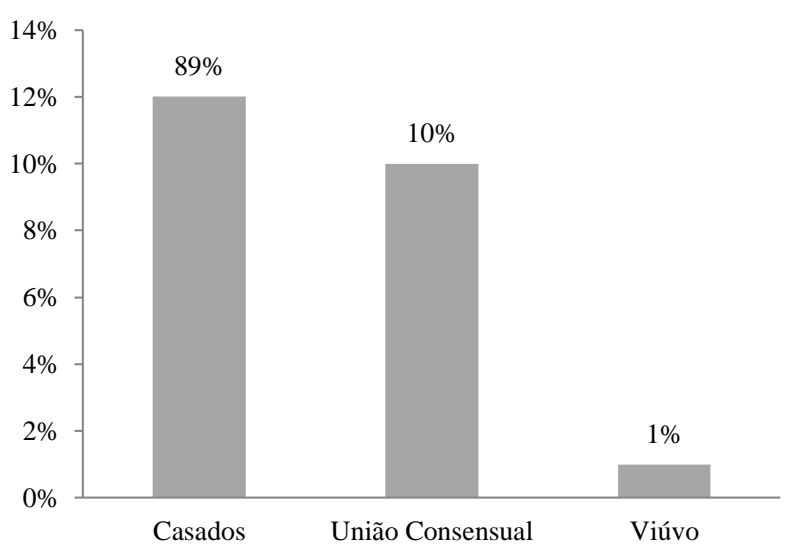

Fonte: Autores (2016)

Como percebe-se a maioria das famílias entrevistadas residem no próprio assentamento (94\%) (Figura 6), em exceção de alguns filhos dos moradores que saíram da comunidade para a cidade em busca de emprego, totalizando a $6 \%$ do total entrevistado.

Figura 6. Porcentagem do número do local de moradia permanente dos moradores no Assentamento Milagre, localizada no município de Apodi, Rio Grande do Norte

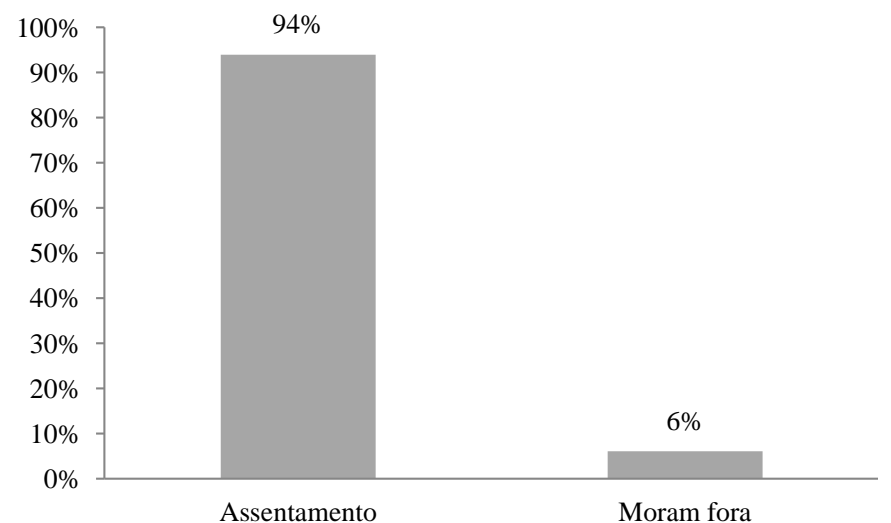

Fonte: Autores (2016)

De acordo com o levantamento sobre a escolaridade por sexo e idade dos moradores, percebemos que as crianças de 03 anos não possuem nenhum acompanhamento escolar. Existe no assentamento apenas uma creche mantida pela prefeitura, composta por alunos cursando o $1^{\circ}$ a $5^{\circ}$ ano, com faixa etária entre 6 a 11 anos de idade. Assim percebe-se a necessidade de escolas para os jovens e adultos.

Segundo as informações obtidas, 95\% dos moradores trabalham na própria agricultura, de forma autônoma ou para outros moradores da comunidade produzindo hortaliças. Um total de $4 \%$ trabalham como pedreiros, ajudantes ou outra atividade e apenas uma pessoa exerce o cargo de professor dentro da comunidade atuando na Creche escolar mantida pela Prefeitura de Apodi-RN, como pode ser visto na Figura 7.
Figura 7. Porcentagem por número de Profissões dos moradores no Assentamento Milagre, localizada no município de Apodi, Rio Grande do Norte

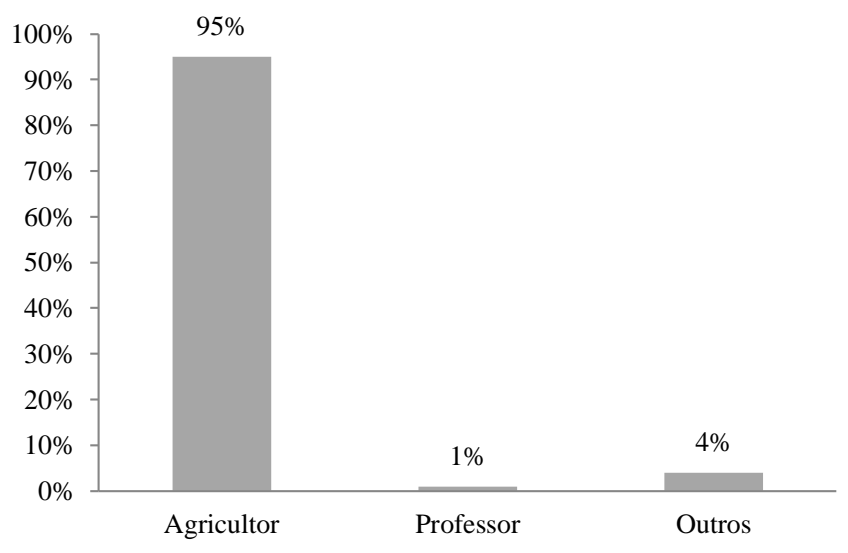

Fonte: Autores (2016)

Quanto à renda salarial do assentado observou-se uma variação dependendo da época do ano, pois, em períodos de estiagem os lucros são bastante reduzidos. Um total de 09 famílias recebem os subsídios do programa Bolsa Família variando entre $\mathrm{R} \$ 70,00$ a $\mathrm{R} \$ 250,00$ reais, apresentando uma renda média variando em torno de 1 a 1,5 salários mínimos.

Quanto ao tempo de residência no assentamento, 15 famílias já moram na comunidade entre 10 a 19 anos, e apenas 8 famílias residem de 1 a 8 anos (Figura 8).

Figura 8. Tempo de moradia dos assentados no Assentamento Milagre, localizada no município de Apodi, Rio Grande do Norte

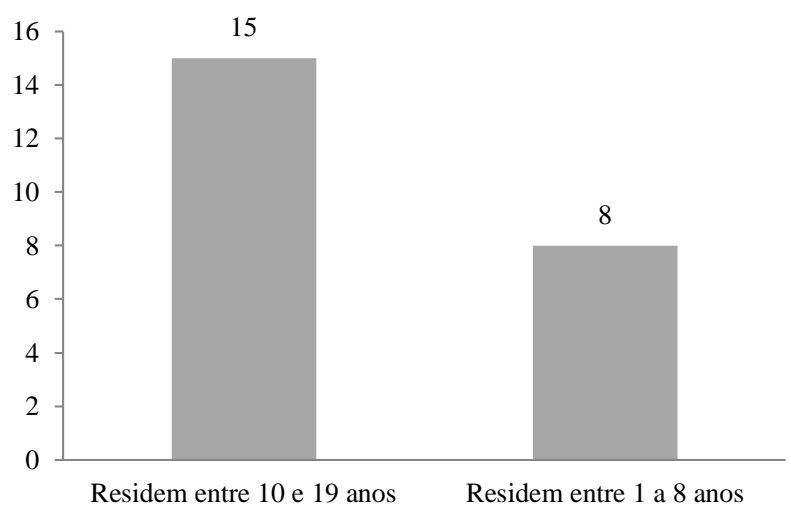

Fonte: Autores (2016)

Percepção dos moradores locais acerca do reuso de água

Ao serem indagados a respeito das mudanças percebidas depois que o assentamento ganhou o saneamento básico todos apontaram nas suas respostas: houve diminuição de insetos, de doenças, há ausência do esgoto a céu aberto escorrendo água no meio da rua, eliminação do mau cheiro, melhorias na paisagem da comunidade, ausência da fossa séptica e o reaproveitamento da água do esgoto. 
Em contrapartida, a percepção socioambiental de um grupo amostral de moradores de condomínios verticais da cidade de Campina Grande, Paraíba, mediante debate para o reuso das águas residuárias, obteve baixa aceitabilidade devido questões de ordem econômica e ideológica. Ainda assim, os atores sociais participantes não se dispuseram a aplicar e/ou investir na reutilização dessas águas em seus apartamentos ou em áreas coletivas, seja em nível de simulação ou projeção, devido desconhecimento do tema ou levantamento de preconceitos sobre a aplicabilidade dos resíduos pós-tratados. (BATISTA et al., 2014)

Quanto ao levantamento das casas conectadas a rede coletora de esgoto a maioria destas são atendidas pelo serviço, e apenas duas casas não estão conectadas. Segundo os moradores dessas duas residências, ainda não é entendido por estes o motivo pelo qual ainda não estão participando, tendo em vista que em suas casas existe toda a instalação feita, faltando apenas a parte que contempla a rua.

Quanto ao destino do óleo de cozinha após o uso, $10 \%$ dos moradores responderam que juntam o óleo para fazer sabão depois de uma oficina que participaram dentro da comunidade, porém $25 \%$ jogam no solo, $23 \%$ utilizam na alimentação animal, 22\% jogam na pia que vai direto para a estação de tratamento e apenas $20 \%$ não utilizam o óleo de cozinha (Figura 9).

Figura 9. Destino do óleo de cozinha consumido no assentamento no Assentamento Milagre, localizada no município de Apodi, Rio Grande do Norte

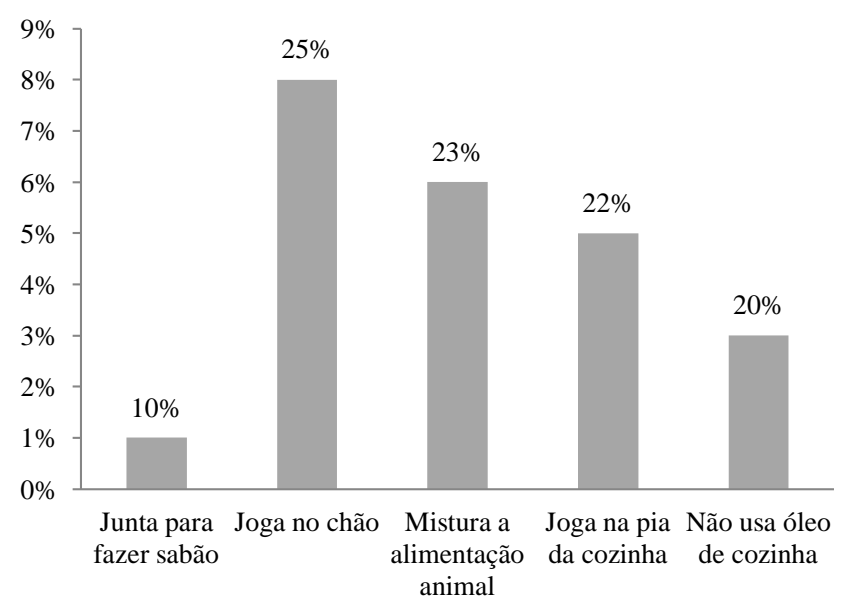

Fonte: Autores (2016)

Quando interrogados sobre a utilização da água de reuso, os entrevistados responderam que o uso era destinado apenas para a irrigação de capim elefante sendo considerado fonte de alimento para os animais existentes na comunidade. De acordo com a percepção dos moradores quanto à qualidade dos experimentos irrigados com a água tratada do esgoto, todos responderam que a mesma apresenta característica boa e excelente.

Em situações nas quais a escassez de água é aguda, a população da comunidade tende a ser mais receptiva em relação ao reuso de água, independentemente de questões culturais. Nesse contexto, a percepção clara de benefícios decorrentes da implantação de tais projetos tende a facilitar a sua aceitação social.

A oposição pública ao reuso resulta de atitudes, crença, preconceitos, falta de conhecimento, medo e desconfiança que são, na maioria das vezes, justificados pelos maus resultados de sistemas de saneamento implantados nos mais variados contextos econômicos, sociais e políticoinstitucionais. (SCHAER-BARBOSA et al., 2014).

\section{CONCLUSÕES}

Observou-se que quanto ao perfil socioeconômico dos moradores entrevistados, a maioria destes residem na comunidade a mais de 10 anos, sendo a agricultura a principal atividade geradora de renda.

Quanto à adoção da prática de reuso de água todos os entrevistados afirmaram melhorias na saúde e no ambiente, tais como: redução da proliferação de vetores e melhor visibilidade da paisagem. Os experimentos irrigados com água tratada para fins de alimentação animal foram bem aceitos pelos moradores.

\section{REFERÊNCIAS}

BATISTA, F.G. A., QUEIROZ, F. R. P. e OLIVEIRA, D. S. Percepção socioambiental do reuso das águas residuárias em condomínios verticais da cidade de Campina Grande - PB. HOLOS, Ano 30, Vol. 6. 2014.

BRASIL. Ministério das Cidades. Transversal: Saneamento básico integrado às comunidades rurais e populações Tradicionais. Guia do profissional em treinamento. Nível 2. Secretaria nacional de saneamento ambiental. Brasília - DF, p. 882009.

EMBRAPA, EMPRESA BRASILEIRA DE PESQUISA AGROPECUÁRIA. Manual de métodos de análise de solo. 2. ed. Brasília: Embrapa Informação Tecnológica, 2009. 624 p

IBGE, INSTITUTO BRASILEIRO DE GEOGRAFIA E ESTATÍSTICA. Censo Demográfico 2010: Características da população e dos domicílios. Resultados do Universo. Rio de Janeiro. 2011.

DOLNICAR, S.; SCHAFER, A.I. Desalinated versus recycled water: public perceptions and profiles of the accepters. Journal of Environmental Management. v.90, p. 888-900, 2009.

HESPANHOL, I. Um novo paradigma para a gestão de recursos hídricos. Estudos Avançados., São Paulo, v. 22, 2008.

HURLIMANN, A. Communit y Attitudes to Recycled Water Use: an Urban Australian Case Study - Part 2. The University of Melbourne, Cooperative Research Centre for Water Quality and Treatment, 2008.

LIRA, R.B. Qualidade do Solo e Avaliação Econômica do Manejo Sustentável da Caatinga no Projeto de Assentamento Moacir Lucena. Apodi, RN. Dissertação de Mestrado Universidade Federal Rural do Semiárido - UFERSA, Mossoró-RN, 2010.

SANTOS, M. E. P.; FADUL, E. . As Sociedades Contemporâneas e a Gestão Pública do Risco. O\&S. Organizações \& Sociedade, v. 15, p. 28-38, 2008. 
SCHAER-BARBOSA, M.; SANTOS, M. E. P.; MEDEIROS,

Y. D. P.. Viabilidade do reúso de água como elemento mitigador dos efeitos da seca no semiárido da Bahia. Ambiente \& Sociedade n São Paulo v. XVII, n. 2 n p. 17-32 n abr.-jun. 2014

SAVI, D.; RIGON, S. P.; ZANELLA, N. A. O cuidado humano no contexto ambiental: ações do enfermeiro nas dimensões ecológicas. In: Anais do Encontro Nacional de Conselhos de Enfermagem - COFEN, 2008; Santa Catarina. Santa Catarina : COFEN; 2008. 